\title{
Clinical findings influencing time to menarche post gonadotropin-releasing hormone agonist therapy in central precocious puberty
}

\author{
Vickie $\mathrm{Wu}^{1}$, \\ Victoria Zhao' ${ }^{2}$, \\ Rula Issa, \\ Meredith Wilkes ${ }^{2}$, \\ Elizabeth Wallach², \\ Robert Rapaport ${ }^{2}$, \\ Christopher Romero², \\ Mabel Yau ${ }^{2}$
}

${ }^{1}$ Department of Pediatrics, Icahn School of Medicine at Mount Sinai, New York, NY, USA

${ }^{2}$ Department of Pediatric Endocrinology, Icahn School of Medicine at Mount Sinai, New York, NY, USA
Received: 28 September, 2020

Revised: 10 December, 2020

Accepted: 2 March, 2021

\section{Address for correspondence:}

Vickie Wu

Department of Pediatrics, Icahn School of Medicine at Mount Sinai, 1 Gustave L. Levy Place, Box 1512, New York, NY 10029, USA

Email: vickie.wu@mountsinai.org https://orcid.org/0000-0002-24363573
Purpose: This study aimed to evaluate the time interval to menarche after gonadotropin-releasing hormone agonist $(\mathrm{GnRHa})$ treatment in females with central precocious puberty (CPP) and to identify factors contributing to timing of menarche.

Methods: We retrospectively reviewed medical records of 39 females with CPP who reached menarche after GnRHa treatment (leuprolide or histrelin). CPP diagnostic criteria were breast development at $<8$ years old, measurable pubertal luteinizing hormone and/or estradiol concentrations, and bone age advancement. Indications to treat were advanced bone age and psychosocial concerns. Descriptive summaries were reported as frequency and proportion for categorical variables and mean and standard deviation for continuous measures. Linear regression models were developed to evaluate the associations of clinical factors with the time interval to menarche.

Results: Mean age was $9.4 \pm 1.6$ years at treatment onset, and treatment duration was $2.2 \pm 1.4$ years. Menarche occurred at $12.6 \pm 1.1$ years, which was $1.04 \pm 0.5$ years after treatment discontinuation. This was negatively associated with Tanner stage of breast development and bone age at treatment onset and change in bone age during treatment. No association was seen between time interval to menarche and treatment duration, medication, or body mass index.

Conclusion: We found the average time interval to menarche after $\mathrm{GnRHa}$ treatment in our population of female patients with CPP to be $1.04 \pm 0.5$ years; this is in agreement with other reports. Tanner stage of breast development, bone age at treatment onset, and change in bone age were negatively associated with time interval to menarche. These data provide clinical correlates that assist providers during anticipatory guidance of patients with CPP after GnRHa treatment.

Keywords: Precocious puberty, Gonadotropin-releasing hormone, Menarche

\section{Highlights}

- Gonadotropin-releasing hormone agonists are used as the main treatment for central precocious puberty.

- Tanner stage of breast development, bone age at treatment onset, and change in bone age were negatively associated with time interval to menarche.

\section{Introduction}

Precocious puberty in females is defined clinically as any sign of puberty before 8 years old. For this disorder, $95 \%$ of cases are due to central precocious puberty (CPP), premature 
activation of the hypothalamic-pituitary-gonadal (HPG) axis. ${ }^{1)}$ Sustained activation can lead to rapidly progressive puberty in a patient who might not be ready for physical changes that include menarche. In addition, CPP leads to premature fusion of epiphyseal growth plates, compromising adult height potential. $^{2,3)}$

Gonadotropin-releasing hormone agonists (GnRHa) are used as the main treatment for CPP. GnRHa binds to GnRH receptors in the anterior pituitary, promoting endocytosis and down-regulation of GnRH receptors. ${ }^{4)}$ This decreases the release of gonadotropins, which leads to decreased estrogen production to prepubertal level. This results in halting the progression of breast development, preventing early menarche, and slowing advanced skeletal maturation and early epiphyseal closure.

Prior studies have shown that menarche begins $0.5-2.5$ years after discontinuation of GnRHa. ${ }^{6-10)}$ However, few studies have evaluated auxological factors that can predict the time interval to menarche after treatment cessation. The aims of this study were to evaluate the time interval to menarche after GnRHa discontinuation and to identify factors that contribute to timing of menarche.

\section{Materials and methods}

\section{Study design}

We performed a retrospective chart review of females with idiopathic CPP who were treated with GnRHa from May 2005 to November 2017, at an academic pediatric endocrinology clinic. The diagnostic criteria for CPP were (1) breast development before 8 years of age ascertained by history or by clinical exam (Tanner stage II or above), (2) measurable pubertal luteinizing hormone ( $\mathrm{LH})$ and/or estradiol concentrations at baseline or in response to GnRH stimulation test, and (3) significant bone age advancement defined as a bone age 2 standard deviations older than chronological age. Patients with an identified etiology of CPP (such as central nervous system pathology) and coexisting endocrinopathies (such as thyroid, ovarian, or adrenal diseases) were excluded (Fig. 1). LH, folliclestimulating hormone, and estradiol were measured by 2 -site electrochemiluminescence at Esoterix Laboratory Services. No patient experienced menarche prior to starting GnRHa treatment.

Of 450 female patients diagnosed with CPP between May 2005 to November 2017, 67 were treated with GnRHa and had documented menarche in their medical record (Fig. 1). Twenty-eight of these patients were excluded: 22 had coexisting endocrinopathies and 6 had CPP with an identified etiology. The remaining 39 patients had idiopathic CPP and were included in this study.

Indications for CPP treatment with GnRHa included poor height prediction, advanced bone age, and psychosocial concerns. Patients were treated with histrelin acetate (50 mg subcutaneous implant yearly, Supprelin LA, Endo Pharmaceuticals, Ireland, Dublin) or leuprolide (intramuscular injections $15 \mathrm{mg}$ every month or $30 \mathrm{mg}$ every 3 months, Lupron Depot-PED, AbbVie Inc., Lake Bluff, IL, USA). The decision on which GnRHa was used depended on the endocrinologist's and family's preferences. All forms of treatment have been validated as adequate treatment modalities in CPP. ${ }^{11)}$ Chronologic age, bone age, and pubertal stage measurements were compared at the start and end of GnRHa treatment. Height, weight, and body mass index (BMI) were expressed as $z$-scores and were calculated based on the Center for Disease Control and Prevention (CDC) growth charts. ${ }^{12)}$ Pubertal progression was staged on the Tanner scale. Bone age was assessed from radiographs of the left hand and wrist and interpreted by a pediatric radiologist using the Greulich-Pyle method. ${ }^{13)}$ Predicted adult height (PAH) was calculated using the BayleyPinneau method. ${ }^{14)}$ Midparental height (MPH) was calculated for these patients using the average of parental heights minus $6.5 \mathrm{~cm}$. After GnRHa treatment, patients were followed until menarche or later. The calculation of the time interval to menarche differed by medication. For histrelin, the time interval started at removal of implant; for leuprolide, the time interval started after the expected duration after the last injection.

\section{Statistical analysis}

Descriptive summaries of patient demographics and clinical characteristics were reported as frequency and proportion

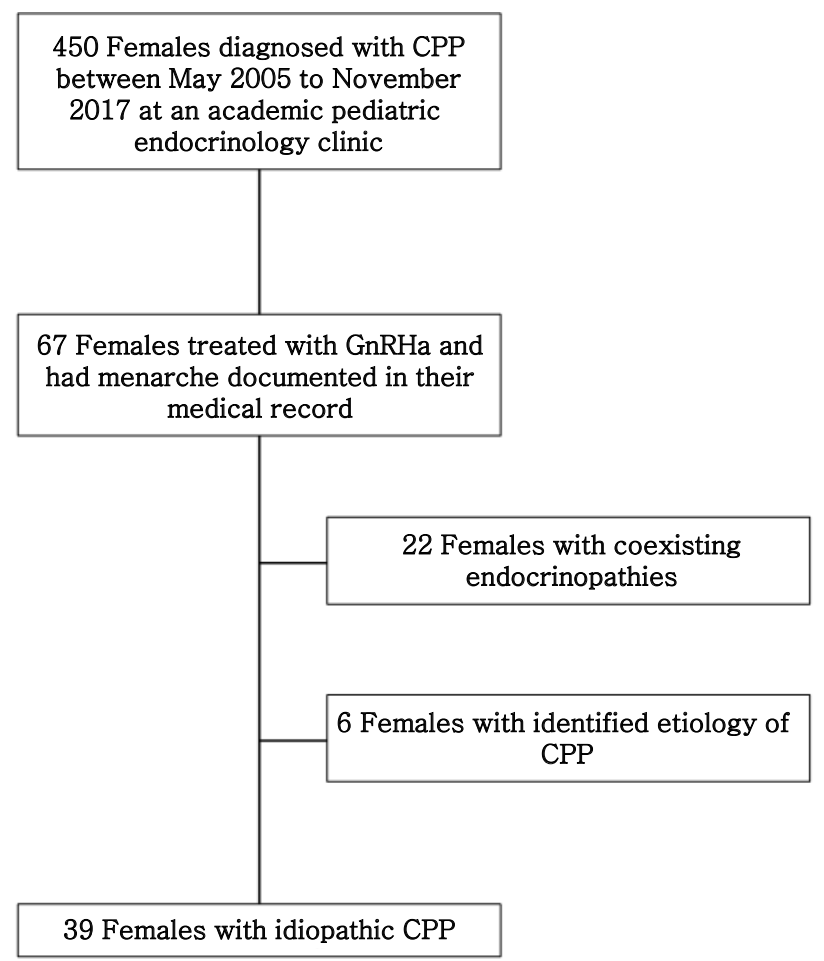

Fig. 1. Study design schematic. CPP, central precocious puberty; GnRHa, gonadotropin-releasing hormone agonist. 
for categorical variables and mean and standard deviation for continuous measures. Linear regression models were developed to evaluate the associations between various clinical factors and the time interval to menarche after the end of treatment. Starting measures at the time of treatment were adjusted in models that assessed the change in physical characteristics. Multiple regression analysis was performed to determine factors influencing time to menarche after the end of treatment. $P$-values of $<0.05$ were considered statistically significant. All analyses were performed using SAS 9.4 (SAS Institute Inc., Cary, NC, USA).

\section{Results}

\section{Clinical and auxological characteristics of patients at start and end of treatment}

Clinical and auxological characteristics of the patients are presented in Table 1. The majority of patients had pubertal LH level prior to starting GnRHa treatment (mean LH, 2.0 1.8 $\mathrm{mIU} / \mathrm{mL}$ ). Six patients required GnRH stimulation testing to confirm CPP biochemically; their mean peak LH level was 7.6 $\mathrm{mIU} / \mathrm{mL}$ (range, $1.1-15 \mathrm{mIU} / \mathrm{mL}$ ) and mean peak estradiol level was $107.5 \mathrm{pg} / \mathrm{mL}$ (range, 4.9-405 pg/mL). The distribution of patient race is reported in Table 1 . There was no significant difference in the distribution of race between medication groups; however, there was a larger percentage of non-Hispanic white females who were treated with leuprolide than with histrelin.

The mean chronologic age and bone age at the start of GnRHa treatment were $9.4 \pm 1.6$ years and $11.2 \pm 1.3$ years, respectively (Table 1). The difference between bone age and chronologic age was $1.8 \pm 1.4$ years at start of treatment. At the start of treatment, the mean height was $139.0 \pm 9.5 \mathrm{~cm}$ and the mean weight was $39.5 \pm 10.6 \mathrm{~kg}$. Of the 39 patients, 13 met CDC diagnostic criteria for pediatric obesity. The mean PAH at the start of treatment was $154.4 \pm 7.6 \mathrm{~cm}$ and the mean MPH was $159.7 \pm 7.2 \mathrm{~cm}$.

At the end of treatment, the mean chronologic age and bone age were $11.6 \pm 1.2$ years and $12.5 \pm 0.9$ years, respectively. The difference between bone age and chronologic age by the end of treatment was $0.9 \pm 1.2$ years.

A majority of the patients at the start of treatment had breast development measured at Tanner stages II (30.8\%) and III $(33.3 \%)$. There was a slight incremental increase in Tanner stage of breast development by the end of treatment, but most were still in stages II (25.6\%) and III (46.2\%).

Of the 39 patients, 18 (46\%) were treated with leuprolide; the other 21 patients were treated with histrelin. Of the patients treated with leuprolide, 13 received the 1-month formulation and 5 received the 3 -month formulation. Table 1 includes a comparison between the patients treated with histrelin and patients treated with leuprolide. Patients treated with leuprolide were significantly older at the end of treatment than were those treated with histrelin $(P=0.02)$. There were no significant differences between the 2 groups in chronologic age at start of treatment, bone age at start or end of treatment, bone agechronologic age at start or end of treatment, Tanner stage at start or end of treatment, height/weight/BMI at start or end of treatment, baseline LH, or treatment duration (all $P>0.05$ ).

\section{Treatment duration and time to menarche}

Patients were treated with $\mathrm{GnRHa}$ for a mean duration of $2.2 \pm 1.4$ years. Mean age at menarche was $12.6 \pm 1.1$ years. Patients reached menarche at $1.04 \pm 0.5$ years after the end of GnRHa

Table 1. Clinical and auxological characteristics at start and end of GnRHa

\begin{tabular}{|c|c|c|c|c|c|c|}
\hline \multirow{2}{*}{ Characteristic } & \multicolumn{2}{|c|}{ All patients $(n=39)$} & \multicolumn{2}{|c|}{ Histrelin patients $(n=21)$} & \multicolumn{2}{|c|}{ Leuprolide patients $(n=18)$} \\
\hline & Start of GnRHa & End of GnRHa & Start of GnRHa & End of GnRHa & Start of GnRHa & End of $\mathrm{GnRHa}$ \\
\hline Chronologic age (yr) & $9.4 \pm 1.6$ & $11.6 \pm 1.2$ & $9.0 \pm 1.5$ & $11.2 \pm 1.0$ & $9.7 \pm 1.7$ & $12.1 \pm 1.2$ \\
\hline Bone age (yr) & $11.2 \pm 1.3$ & $12.5 \pm 0.9$ & $11.0 \pm 1.5$ & $12.4 \pm 0.8$ & $11.4 \pm 1.1$ & $12.6 \pm 3.1$ \\
\hline Bone age-chronologic age (yr) & $1.8 \pm 1.4$ & $0.9 \pm 1.2$ & $2.0 \pm 1.4$ & $1.3 \pm 1.4$ & $1.5 \pm 1.2$ & $0.6 \pm 0.8$ \\
\hline Tanner stage breast development & $3 \pm 1$ & $3 \pm 1$ & $3 \pm 1$ & $3 \pm 1$ & $3 \pm 1$ & $3 \pm 1$ \\
\hline Height $(\mathrm{cm})$ & $139.0 \pm 9.5$ & $149.4 \pm 7.1$ & $138.2 \pm 9.2$ & $148.3 \pm 7.3$ & $139.9 \pm 10.0$ & $150.7 \pm 6.9$ \\
\hline Height z-score & $0.5 \pm 1.2$ & $0.2 \pm 1.2$ & $0.7 \pm 1.4$ & $0.4 \pm 1.2$ & $0.4 \pm 0.9$ & $-0.1 \pm 1.1$ \\
\hline Weight (kg) & $39.5 \pm 10.6$ & $50.6 \pm 13.2$ & $38.3 \pm 11.1$ & $48.9 \pm 14.3$ & $40.9 \pm 10.1$ & $52.5 \pm 11.6$ \\
\hline Weight z-score & $0.9 \pm 1.1$ & $0.84 \pm 1.2$ & $0.9 \pm 1.4$ & $0.8 \pm 1.4$ & $1.0 \pm 0.7$ & $0.9 \pm 0.9$ \\
\hline $\mathrm{BMI}\left(\mathrm{kg} / \mathrm{m}^{2}\right)$ & $20.2 \pm 3.7$ & $22.4 \pm 4.6$ & $19.7 \pm 3.9$ & $21.9 \pm 5.2$ & $20.7 \pm 3.3$ & $23.0 \pm 3.9$ \\
\hline BMI z-score & $0.9 \pm 1.0$ & $0.9 \pm 1.1$ & $0.8 \pm 1.2$ & $0.8 \pm 1.4$ & $1.1 \pm 0.7$ & $1.1 \pm 0.7$ \\
\hline Baseline LH (mIU/mL) & $2.0 \pm 1.8$ & N/A & $2.0 \pm 1.8$ & N/A & $1.9 \pm 1.8$ & N/A \\
\hline Treatment duration (yr) & \multicolumn{2}{|c|}{$2.2 \pm 1.4$} & \multicolumn{2}{|c|}{$2.1 \pm 1.2$} & \multicolumn{2}{|c|}{$2.3 \pm 1.6$} \\
\hline \multicolumn{7}{|l|}{ Race } \\
\hline Non-Hispanic White & \multicolumn{2}{|c|}{$20(51.3)$} & \multicolumn{2}{|c|}{$8(38.1)$} & \multicolumn{2}{|c|}{$12(66.6)$} \\
\hline Hispanic & \multicolumn{2}{|c|}{$8(20.5)$} & \multicolumn{2}{|c|}{$5(23.8)$} & \multicolumn{2}{|c|}{$3(16.7)$} \\
\hline Non-Hispanic Black & \multicolumn{2}{|c|}{$8(20.5)$} & \multicolumn{2}{|c|}{$5(23.8)$} & \multicolumn{2}{|c|}{$3(16.7)$} \\
\hline Asian & \multicolumn{2}{|c|}{$3(7.7)$} & \multicolumn{2}{|c|}{$3(14.3)$} & \multicolumn{2}{|c|}{$0(0)$} \\
\hline
\end{tabular}

Values are presented as mean \pm standard deviation or number (\%).

GnRHa, gonadotropin-releasing hormone agonists; BMl, body mass index; LH, luteinizing hormone; N/A, not applicable. 
treatment (Fig. 2). In total, 54\% of patients reached menarche by 1 year after the end of GnRHa treatment, and 44\% reached menarche by 2 years.

Clinical factors associated with the time interval to menarche from the end of treatment are presented in Table 2. Time interval to menarche was found to be negatively associated with bone age at start of treatment, Tanner stage of breast development at start of treatment, and change in bone age from start to end of treatment (all $P<0.05)$. As bone age at the start of treatment advanced, the interval to menarche decreased $(\beta=-0.16 ; 95 \%$ confidence interval $[\mathrm{CI}],-0.27$ to $-0.05 ; P=0.005)$. Similarly, increased Tanner stage prior to treatment was associated with shorter interval to menarche. Moreover, after adjusting for initial bone age, a greater change in bone age over the course of the treatment period was significantly associated with a shorter interval to menarche $(\beta=-0.25 ; 95 \% \mathrm{CI},-0.44$ to $-0.07 ; P=0.009)$. No association was observed between time to menarche and treatment duration, medication, or BMI.

In the multiple regression analysis, clinically relevant variables at the start of treatment were Tanner stage, age, height, weight, BMI, bone age, and height prediction and were explored and considered as potential candidates. We performed backward selection with a $P$-value threshold of $<0.15$ to obtain the final model for time to menarche after medication. In the final model, the overall model F-statistic $P$-value was $0.01\left(\mathrm{R}^{2}=0.36\right)$. This suggests an association in at least one of the parameters; however, the more parsimonious model would be with only Tanner stage or only bone age (see Table 2 ). Table 3 shows that, as Tanner stage and bone age increased at the start of treatment, the time interval from end of treatment to menarche was shorter in duration.

\section{Discussion}

We performed a retrospective chart review of 39 females

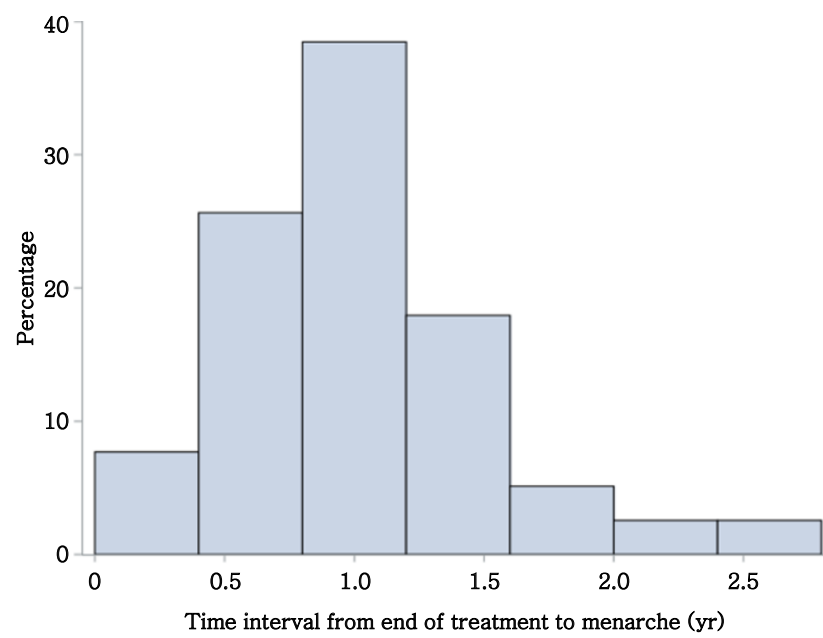

Fig. 2. Distribution of time intervals from end of gonadotropin-releasing hormone agonist treatment to menarche. with CPP who were treated with GnRHa and evaluated age of menarche, time interval to menarche after cessation of GnRHa treatment, and factors that influence time to menarche. Menarche in our patients treated with GnRHa occurred at $12.6 \pm 1.1$ years, comparable to that of the general population. Given that one of the goals of treatment in females with CPP is to realign pubertal development to that of their peers, GnRHa therapy was able to help achieve this goal in our patients. This is consistent with previous research that examined age of menarche post-GnRHa treatment. Baek et al. ${ }^{6}$ ) reported menarche at $11.9 \pm 0.7$ years, Heger et al. ${ }^{15)}$ reported menarche at $12.3 \pm 1.4$ years, and Lee et al. ${ }^{16)}$ reported menarche at $12.6 \pm 0.6$ years after GnRHa treatment.

We found an average time interval to menarche after GnRHa treatment in our population of female patients with CPP of $12 \pm 6$ months. This was similar to previous studies: Baek

Table 2. Univariable analysis between time interval to menarche and multiple factors

\begin{tabular}{|c|c|c|}
\hline Variable & $\beta$ Estimate $(95 \% \mathrm{Cl})$ & $P$-value \\
\hline Medication & & 0.70 \\
\hline Histrelin & Reference & \\
\hline Leuprolide & $-0.07(-0.40$ to 0.27$)$ & \\
\hline Tanner stage start & & 0.006 \\
\hline 2 & Reference & \\
\hline 3 & $-0.36(-0.74$ to 0.01$)$ & \\
\hline $4 / 5$ & $-0.66(-1.06$ to -0.27$)$ & \\
\hline Age start & $-0.09(-0.19$ to 0.01$)$ & 0.08 \\
\hline Treatment duration & $-0.11(-0.27$ to 0.06$)$ & 0.19 \\
\hline Height start & $-0.01(-0.03$ to 0.01$)$ & 0.17 \\
\hline$\Delta$ Height $^{*}$ & $0.003(-0.04$ to 0.05$)$ & 0.91 \\
\hline Weight start & $-0.02(-0.03$ to 0.0001$)$ & 0.05 \\
\hline$\Delta$ Weight $^{*}$ & $-0.01(-0.04$ to 0.03$)$ & 0.09 \\
\hline BMI start & $-0.04(-0.09$ to 0.002$)$ & 0.06 \\
\hline$\triangle \mathrm{BMI}^{*}$ & $-0.01(-0.10$ to 0.08$)$ & 0.09 \\
\hline BMI z-score start & $-0.09(-0.26$ to 0.07$)$ & 0.25 \\
\hline$\triangle$ BMI z-score $^{*}$ & $-0.02(-0.34$ to 0.31$)$ & 0.92 \\
\hline Bone age start & $-0.16(-0.27$ to -0.05$)$ & 0.005 \\
\hline$\Delta$ Bone age $^{*}$ & $-0.25(-0.44$ to -0.07$)$ & 0.009 \\
\hline PAH start & $-0.01(-0.04$ to 0.01$)$ & 0.17 \\
\hline \multicolumn{3}{|c|}{$\begin{array}{l}\mathrm{Cl} \text {, confidence interval; BMI, body mass index; } \mathrm{PAH} \text {, predicted } \\
\text { adult height. } \\
\text { *Adjusts for the respective starting values measured at the time } \\
\text { of medication. }\end{array}$} \\
\hline
\end{tabular}

Table 3. Multiple regression analysis on time interval from end of gonadotropin-releasing hormone agonist treatment to menarche

\begin{tabular}{lcc}
\hline Variable & Estimate $(95 \% \mathrm{Cl})$ & $P$-value \\
\hline Tanner stage start & Reference & 0.08 \\
2 & $-0.30(-0.66$ to 0.07$)$ & 0.11 \\
3 & $-0.47(-0.88$ to -0.06$)$ & 0.03 \\
$4 / 5$ & $-0.09(-0.21$ to 0.03$)$ & 0.13 \\
\hline
\end{tabular}

$\mathrm{Cl}$, confidence interval. 
et al. ${ }^{6)}$ observed the time interval to be $14 \pm 5.6$ months after stopping leuprolide injections, Gillis et al. ${ }^{7)}$ observed $9.3 \pm 1.5$ months to menarche after histrelin implant removal, and Neely et al. ${ }^{8)}$ observed $18 \pm 6$ months to menarche after cessation of leuprolide. In our study, there was no difference in time interval to menarche between patients who received leuprolide and those who received histrelin; this is a novel finding, as no other study has reported comparisons between leuprolide and histrelin. Gillis et al. ${ }^{7)}$ performed a similar study but compared histrelin implant to triptorelin depot. We found this to be a valuable observation in regard to patient counseling as efficacy of treatment was similar regardless of GnRH agonist therapy and allowed puberty to resume appropriately. Time interval to menarche was found to be negatively associated with bone age at start of treatment, Tanner stage of breast development at start of treatment, and change in bone age from start to end of treatment. Thus, females reached menarche sooner after discontinuation of GnRHa treatment when treatment was started later in puberty. In contrast, there was no association between time to menarche and treatment duration, medication, or BMI. Aside from reports by Baek et al. ${ }^{6}$ and Arrigo et al., ${ }^{17)}$ this is the only study to examine auxological factors that can predict time interval to menarche post-GnRHa treatment. We believe that these are important findings with clinical utility. These auxological factors and effects of treatment are typically counseling points parents seek at the time of starting treatment. Although the goal is to safely pause puberty, the provider needs to be prepared to appropriately advise when parents seek counsel on GnRH agonist therapy during and post-treatment. The questions relate to timing of menarche, the factors that can affect this duration to menarche, and whether treatment duration affects restoration of HPG axis function.

One of the treatment indications of GnRHa for females with CPP is to delay physical changes and subsequent menarche to minimize psychosocial distress. Precocious puberty has been associated with increased delinquency and physical aggression, and females with early puberty have been suggested to face greater social isolation and bullying than their peers. ${ }^{18,19)}$ Some studies have shown increased stress and anxiety in females with precocious puberty. ${ }^{20,21)}$ These data on time interval to menarche after GnRHa treatment and clinical factors that influence this time interval can aid clinicians in counseling parents and reduce some of the parental and patient concerns. We believe that data on time interval to menarche after GnRHa treatment and an evidence-based discussion on factors that influence this time interval will reduce many parental and patient concerns at the start and end of therapy.

Precocious puberty also can lead to stunted growth as a consequence of premature growth plate fusion. However, there are conflicting reports on the height outcomes in females with CPP who were treated with GnRHa. ${ }^{22)}$ Lazar et al. ${ }^{23)}$ observed little or no increase in final adult height (FAH) if GnRHa treatment was started after 8 years of age. In contrast, other studies showed that GnRHa treatment improved height outcomes even in slightly older patients. ${ }^{16,24-26)}$ This suggests that other factors such as degree of bone age advancement, age of pubertal onset, and height are better predictors of final height than is age at treatment onset. ${ }^{16)}$ Heger et al ${ }^{15)}$ reported that females with CPP who received GnRHa treatment had FAH that was significantly higher than the pretreatment PAH (FAH was $160.6 \pm 8.0 \mathrm{~cm}$, pretreatment PAH $154.9 \pm 9.6 \mathrm{~cm}$ ). Jung et al. ${ }^{27)}$ reported similar results (FAH was $160.4 \pm 4.2 \mathrm{~cm}$, pretreatment PAH $156.6 \pm 3.9 \mathrm{~cm}$ ). In contrast, Korkmaz et al. ${ }^{28)}$ found no significant difference in final height between treated and untreated females in addition to PAH being greater than final height. Analysis of height outcome was not performed in this study as $36 \%$ of the patients were treated with growth hormone therapy, and FAH was available in only $44 \%$ of our patients.

One limitation of our study was a small sample size compared to most other studies. A larger sample size would improve the statistical power of the results and allow the researchers to more robustly compare medications. Also, we did not have an untreated control group of females with CPP who could be followed until menarche. While the patients in this study started GnRHa treatment at a late age, the timing of presentation was dependent on pediatrician referral and, therefore, impacted the age at the start of treatment. Only $49 \%$ of our patients had information on maternal age at menarche. If more data were available, the researchers would have been interested to study any correlation between patient age at menarche and maternal age at menarche.

In conclusion, the time from the end of treatment to menarche ranged from 0.5 to 1.5 years. The factors negatively associated with the time interval to menarche were Tanner stage of breast development at treatment onset, bone age at treatment onset, and change in bone age. These data provide clinical correlates that assist providers during anticipatory guidance of patients after treatment of CPP with GnRHa.

\section{Ethical statement}

The study was approved by the Icahn School of Medicine Institutional Review Board (IRB-19-02148), which waived the need for informed consent.

\section{Conflict of interest}

No potential conflict of interest relevant to this article was reported.

\section{Acknowledgments}

The authors wish to thank Stephanie Pan, MS, for her assistance in statistical support.

\section{References}

1. Rosenfield RL, Cooke DW, Radovick S. Puberty and its 
disorders in the female. In: Sperling MA, editor. Pediatric endocrinology. 4th ed. Philadelphia (PA): Elsevier/ Saunders, 2014:569-663.e1.

2. Lee PA. Central precocious puberty. An overview of diagnosis, treatment, and outcome. Endocrinol Metab Clin North Am 1999;28:901-18, xi.

3. Carel JC, Lahlou N, Roger M, Chaussain JL. Precocious puberty and statural growth. Hum Reprod Update 2004;10:135-47.

4. Brito VN, Spinola-Castro AM, Kochi C, Kopacek C, Silva PC, Guerra-Junior G. Central precocious puberty: revisiting the diagnosis and therapeutic management. Arch Endocrinol Metab 2016;60:163-72.

5. Carel JC, Eugster EA, Rogol A, Ghizzoni L, Palmert MR, Antoniazzi F, et al. Consensus statement on the use of gonadotropin-releasing hormone analogs in children. Pediatrics 2009;123:e752-62.

6. Baek JW, Nam HK, Jin D, Oh YJ, Rhie YJ, Lee KH. Age of menarche and near adult height after long-term gonadotropin-releasing hormone agonist treatment in girls with central precocious puberty. Ann Pediatr Endocrinol Metab 2014;19:27-31.

7. Gillis D, Karavani G, Hirsch HJ, Strich D. Time to menarche and final height after histrelin implant treatment for central precocious puberty. J Pediatr 2013;163:532-6.

8. Neely EK, Lee PA, Bloch CA, Larsen L, Yang D, MattiaGoldberg C, et al. Leuprolide acetate 1-month depot for central precocious puberty: hormonal suppression and recovery. Int J Pediatr Endocrinol 2010;2010:398639.

9. Tanaka T, Niimi H, Matsuo N, Fujieda K, Tachibana K, Ohyama K, et al. Results of long-term follow-up after treatment of central precocious puberty with leuprorelin acetate: evaluation of effectiveness of treatment and recovery of gonadal function. The TAP-144-SR Japanese Study Group on Central Precocious Puberty. J Clin Endocrinol Metab 2005;90:1371-6.

10. Paterson WF, McNeill E, Young D, Donaldson MD. Auxological outcome and time to menarche following longacting goserelin therapy in girls with central precocious or early puberty. Clin Endocrinol (Oxf) 2004;61:626-34.

11. Fuqua JS. Treatment and outcomes of precocious puberty: an update. J Clin Endocrinol Metab 2013;98:2198-207.

12. Kuczmarski RJ, Ogden CL, Guo SS, Grummer-Strawn LM, Flegal KM, Mei Z, et al. 2000 CDC Growth Charts for the United States: methods and development. Vital Health Stat 11 2002;(246):1-190.

13. Greulich W, Pyle S. Radiographic atlas of skeletal development of the hand and wrist. 2nd ed. Stanford (CA): Stanford University Press, 1959.

14. Bayley N, Pinneau SR. Tables for predicting adult height from skeletal age: revised for use with the Greulich-Pyle hand standards. J Pediatr 1952;40:423-41.

15. Heger S, Partsch CJ, Sippell WG. Long-term outcome after depot gonadotropin-releasing hormone agonist treatment of central precocious puberty: final height, body proportions, body composition, bone mineral density, and reproductive function. J Clin Endocrinol Metab 1999;84:4583-90.

16. Lee HS, Yoon JS, Park KJ, Hwang JS. Increased final adult height by gonadotropin-releasing hormone agonist in girls with idiopathic central precocious puberty. PLoS One 2018;13:e0201906.

17. Arrigo T, De Luca F, Antoniazzi F, Galluzzi F, Iughetti L, Pasquino AM, et al. Menstrual cycle pattern during the first gynaecological years in girls with precocious puberty following gonadotropin-releasing hormone analogue treatment. Eur J Pediatr 2007;166:73-4.

18. Mrug S, Elliott MN, Davies S, Tortolero SR, Cuccaro P, Schuster MA. Early puberty, negative peer influence, and problem behaviors in adolescent girls. Pediatrics 2014;133:7-14.

19. Schoelwer MJ, Donahue KL, Bryk K, Didrick P, Berenbaum SA, Eugster EA. Psychological assessment of mothers and their daughters at the time of diagnosis of precocious puberty. Int J Pediatr Endocrinol 2015;2015:5.

20. Menk TAS, Inácio M, Macedo DB, Bessa DS, Latronico AC, Mendonca BB, et al. Assessment of stress levels in girls with central precocious puberty before and during long-acting gonadotropin-releasing hormone agonist treatment: a pilot study. J Pediatr Endocrinol Metab 2017;30:657-62.

21. Mercader-Yus E, Neipp-López MC, Gómez-Méndez P, Vargas-Torcal F, Gelves-Ospina M, Puerta-Morales L, et al. Anxiety, self-esteem and body image in girls with precocious puberty. Rev Colomb Psiquiatr 2018;47:229-36.

22. Bereket A. A critical appraisal of the effect of gonadotropinreleasing hormon analog treatment on adult height of girls with central precocious puberty. J Clin Res Pediatr Endocrinol 2017;9:33-48.

23. Lazar L, Padoa A, Phillip M. Growth pattern and final height after cessation of gonadotropin-suppressive therapy in girls with central sexual precocity. J Clin Endocrinol Metab 2007;92:3483-9.

24. Klein KO, Dragnic S, Soliman AM, Bacher P. Predictors of bone maturation, growth rate and adult height in children with central precocious puberty treated with depot leuprolide acetate. J Pediatr Endocrinol Metab 2018;31:65563.

25. Micillo M, Salerno M, Officioso A, Perna E, Gasparini N, Pisaturo L, et al. Near final height after GnRH agonist treatment in central precocious puberty. J Pediatr Endocrinol Metab 2000;13 Suppl 1:787-90.

26. Pasquino AM, Pucarelli I, Accardo F, Demiraj V, Segni M, Di Nardo R. Long-term observation of 87 girls with idiopathic central precocious puberty treated with gonadotropinreleasing hormone analogs: impact on adult height, body mass index, bone mineral content, and reproductive function. J Clin Endocrinol Metab 2008;93:190-5.

27. Jung MK, Song KC, Kwon AR, Chae HW, Kim DH, Kim HS. Adult height in girls with central precocious puberty treated with gonadotropin-releasing hormone agonist 
with or without growth hormone. Ann Pediatr Endocrinol Metab 2014;19:214-9.

28. Korkmaz O, Sari G, Mecidov I, Ozen S, Goksen D, Darcan $\mathrm{S}$. The gonadotropin-releasing hormone analogue therapy may not impact final height in precocious puberty of girls with onset of puberty aged 6 - 8 years. J Clin Med Res 2019;11:133-6. 